\title{
Rectal Kaposi Sarcoma
}

National Cancer Institute

\section{Source}

National Cancer Institute. Rectal Kaposi Sarcoma. NCI Thesaurus. Code C5550.

A Kaposi sarcoma arising from the rectum. 